Coronary heart disease and drinking water. A search in two Finnish male cohorts for epidemiologic evidence of a water factor. 7 Chronic Dis $1975 ; 28: 259-87$

16 Hatano S, Nishi $Y$, Usui $T$. Copper levels in plasma and erythrocytes in healthy Japanese children and adults. Am 7 Clin Nutr 1982;35:120-6.

17 Kant AK, Moser-Veillon PB, Reynolds RD. Dietary intakes and plasma concentrations of zinc, copper, magnesium, and selenium of voung, middle aged and older men. Nutrition Research 1989;9:717-24.

18 Singh A, Dav BA, DeBold JE, Trostmann UH, Bernier LL, Deuster PA. Magnesium, zinc, and copper status of US navy SEAL trainees. A $m \mathcal{F}$ Clin Nutr 1989:49:695-700.

19 Hiisvirta L, Lehto J, Kumpulainen J, Koivistoinen P, Pitkänen L. Metals in main waters. Finn $\mathcal{F}$ Water Econ Hydr Agr Eng 1985;26:30

20 Mäkinen P. Problems of the water supply of rural areas caused by acidification and acid ground waters. Helsinki: Water and Environment 38, the National and acid ground waters. Helsinki. Water and Envire

21 WHO Monica Project. WHO Monica project: risk factors. In $f$ Epidemiol 1989;18(suppl 1):S46-55.

22 Shamberger RJ. Selenium. In: Frieden E, ed. Biochemistry of the essential ultratrace elements. New York: Plenum Press, 1984:201-37.

23 Halliwell B, Gutteridge JMC. Free radicals in biology and medicine. 2nd ed. Oxford: Clarendon Press, 1989

24 Esterbauer H, Strigl G, Puhl H, Rotheneder M. Continuous monitoring of in vitro oxidation of human low density lipoprotein. Free Radical Research Communicutions 1989;6:67-75.

25 Lewis KO, Paton A. Could superoxide cause cirrhosis? Lancel 1982; ; 188-9 26 Jeandel C, Nicolas MB, Dubois F, Nabet-Belleville F, Penin F, Guny G. Lipid peroxidation and free radical scavengers in Alzheimer's disease. (jecontolog 1989;35:275-82

27 Lloyd B, Lloyd RS, Clayton BE. Effect of smoking, alcohol, and other factors on the selenium status of a healthy population. 7 Epidemiol Community Health 1983;37:213-7.

28 Moore JA, Noiva R, Wells IC. Selenium concentrations in plasma of patient with arteriographically defined coronary atherosclerosis. Clin Chem 1984 30:1171-3.

29 Schectman $\mathrm{G}$, Byrd JC, Gruchow HW. The influence of smoking on vitamin $\mathrm{C}$ status in adults. Am F Public Health 1989;79:158-62.

30 Ernst E, Hammerschmidt DE, Bagge U, Matral A, Dormandy JA. Leucocytes and the risk of ischemic diseases. FAMA 1987;257:2318-24.

31 Cathcart MK, Morel DW, Chisolm GM. Monocytes and neutrophils oxidize low density lipoprotein making it cytotoxic. I Leukocyte Biol 1985;38: $342-50$.

32 Quinn MT, Parthasarathy S, Fong LG, Steinberg D. Oxidatively modified low density lipoproteins: a potential role in recruitment and retention of monocyte/macrophages during atherogenesis. Proc Natl Acad Sci 1987;84: 2995-8.

33 Ludwig PW, Hunninghake DB, Hoidal JR. Increased leucocyte oxidative metabolism in hyperlipoproteinaemia. Lancet 1982;i:348-50.

(Accepted l February 1991)

\section{Frequency of carriers of cystic fibrosis gene among patients with myeloid malignancy and melanoma}

\author{
N Warren, J A Holmes, L Al-Jader, \\ R R West, D C Lewis, R A Padua
}

University of Wales College of Medicine, Cardiff CF4 4XN

$\mathrm{N}$ Warren, BSC, research officer in surgery

J A Holmes, MRCP, lecturer in haematology

L Al-Jader, MB, clinical assistant in medical genetics

$\mathrm{R} R$ West, PHD, reader in epidemiology

D C Lewis, FRCS, research

fellow in surgery

R A Padua, PHD, senior

lecturer in haematology

Correspondence to:

Dr R A Padua, Leukaemia

Research Fund,

Preleukaemia Unit,

Department of

Haematology, University of

Wales College of Medicine, Cardiff CF4 $4 \mathrm{XN}$.

BMF 1991;302:760-1

Cystic fibrosis is an autosomal recessive disease with a prevalence of carriers of about $5 \%$ and an overall incidence in white populations of 1 in 2000 live births. The cystic fibrosis gene has been cloned and sequenced, and a deletion $(\Delta \mathrm{F} 508)$ that causes the loss of a phenylalanine residue at amino acid position 508 has been mapped.' This deletion accounts for $74 \%$ of carriers in Britain.?

In a preliminary report of an epidemiological survey of families affected by cystic fibrosis an association between putative carrier status for cystic fibrosis and leukaemia (most notably acute myeloid leukaemia) was found. ${ }^{3+}$

To test this association we studied the frequency of $\Delta$ F508 in DNA from patients with acute myeloid leukaemia, the myelodysplastic syndrome, and malignant melanoma (as a solid tumour control) and from normal subjects.

\section{Patients, methods, and results}

Normal DNA was obtained at random from healthy donors from the blood transfusion service. Donors were screened according to the blood service's protocols, which included an extensive questionnaire, interview by the attending doctor, and check of haemoglobin concentrations and blood pressure. These samples were not consecutive. Samples from patients with acute myeloid leukaemia and the myelodysplastic syndrome were obtained from the department of

Carriers of $\triangle F 508$ in patients with and without malignancy

\begin{tabular}{|c|c|c|c|c|}
\hline & \multirow{2}{*}{$\begin{array}{l}\text { No } \\
\text { studied }\end{array}$} & \multicolumn{2}{|c|}{ No of $\Delta F 508$ carriers } & \multirow{2}{*}{$\begin{array}{c}\text { Odds ratio } \\
\text { ( } 95 \% \text { confidence interval) }\end{array}$} \\
\hline & & Expected & Observed & \\
\hline \multicolumn{5}{|l|}{ Patients with: } \\
\hline Myelodysplastic syndrome & 159 & 6 & 7 & $0.89(0.28$ to 2.77$)$ \\
\hline Acute myeloid leukaemia & 137 & 5 & 7 & $1.04(0.33$ to 3.25$)$ \\
\hline Naevus & 20 & 1 & 1 & $1.01(0.12$ to 8.55$)$ \\
\hline Melanoma & 166 & 6 & $0 \dagger$ & $0(0$ to 0.64$)$ \\
\hline Normal subjects & 162 & 6 & $8 t$ & \\
\hline
\end{tabular}

^Using Cornfelds method.

tComparison of patients with melanoma and normal subjects, $\mathrm{p}=0 \cdot 007$ (Fisher's exact two tailed test). haematology and from those patients with melanoma from the department of surgery and subsequent follow up clinics. The patients were selected at random and the sample size was determined by the availabilty of material.

The samples were either peripheral blood, bone marrow, histological specimens, fresh washes of the buccal mucosa, or paraffin embedded tissue blocks. They were screened for $\Delta \mathrm{F} 508$ by using a modified polymerase chain reaction procedure and polyacrylamide gel electrophoresis. Direct sequencing of the products of the polymerase chain reaction confirmed the published sequences for the wild type and mutated alleles.

The table shows the results of the screening for the deletion. The expected number of carriers of $\Delta F 508$ were estimated on the basis of the putative gene frequency in the population, which is $74 \%$ of $1 / 20=1 / 27$. Most of the groups studied had the normal expected frequency for carriers. Except for patients with melanomas, the differences found were not significant.

Unexpectedly, no carriers were found among 166 patients with melanoma. This differed significantly from the eight carriers found among 162 normal subjects ( $p=0 \cdot 007$, Fisher's exact two tailed test). In 91 of the patients with melanomas the constitutional genotype was confirmed by analysis of tissue from adjacent skin, blood, or buccal mucosal cells. In a genetic survey of first and second degree relatives of patients with cystic fibrosis two skin cancers were found. Both of these were basal cell carcinomas not melanomas, although among the number of patients studied the expected frequency of melanoma was less than one $(3000 / 10000=0 \cdot 3)$.

\section{Comment}

This study shows that carriers of $\Delta \mathrm{F} 508$ may be protected from developing melanoma. The finding of a single carrier in the group with naevus suggests that cell lineage specificity is not a possible explanation for this finding. The case for leukaemias has yet to be proved: to reach significance with a carrier to noncarrier ratio of $2: 1$ roughly 600 patients in each leukaemic group would have to be analysed.

Carriers of one cystic fibrosis gene show no symptoms of the disease. This has led to the suggestion that heterozygosity for cystic fibrosis confers some form of biological advantage that has allowed the potentially lethal gene to be retained in the population at a high frequency. The incidence of melanoma in the United Kingdom, however, is 10 in 100000 , and therefore it does not seem that protection against only melanoma 
by heterozygosity for cystic fibrosis would confer biological advantage. The $\Delta \mathrm{F} 508$ is most common in white populations in the United Kingdom, United States, and The Netherlands but has a greatly reduced incidence in southern European populations ${ }^{5}$ and in black and Mongoloid populations. Noticeably, fair skinned people are the most susceptible to melanoma and so would benefit the most from the possibly protective heterozygous state.

Our finding of an inverse association between being a carrier of $\triangle F 508$ and melanoma was unexpected. It suggests that the presence of a genetic marker (or gene defect) may protect against melanoma.

We thank $\mathrm{L}$ Meredith for providing some of the data on normal subjects; P Laidler, J A Whittaker, L Hughes, A
Jacobs, and P Harper for providing clinical samples and useful discussion; and D C Hughes, G Carter, V K Shukla, and C Farr for preparing the DNA samples. This work was funded by the Cancer Research Campaign and Leukaemia Research Fund of Great Britain

1 Rommens JM, Ianuzzi MC, Kerem B, et al. Identification of the cystic fibrosis gene: chromosome walking and jumping. Science 1989;245: 1059-65.

2 McIntosh I, Lorenzo ML, Brock DJH. Frequency of delta F508 mutation on vistic fibrosis chromosomes in UK. Lancet 1989;ii: 1404-5.

3 Al-Jader LN, W'est RR, Goodchild MC, Harper PS. Mortality from leukaemi among relatives of patients with cystic fibrosis. BMJ 1989;298:16t.

4 Al-Jader LN, West RR, Holmes JA, Meredith L, Goodchild MC, Harper PS. Leukacmia mortality among relatives of cystic fibrosis patients. Arch Dis Child 1991:66:317.9.

5 Estivill X, Chillon M, Casals T, et al. Delta F508 gene deletion in cystic fibrosis in southern Europe. Lancet 1989;ii:140.

(Accepted 21 fanuary 1991)

\section{Suicide among men in the highlands of Scotland}

\author{
Iain K Crombie
}

\section{Department of}

Epidemiology and Public

Health, Ninewells Hospital

and Medical School,

Dundee DD1 9SY

Iain K Crombie, PHD, senior lecturer

BMF 1991;302:761-2
Suicide in Scotland has attracted attention because of an unexplained, rapid rise in the rates among men.' A recent study found no association between suicide rates and levels of unemployment. ${ }^{2}$ This was unexpected as unemployment is known to be associated with many measures of social deprivation that might themselves be associated with high suicide rates. ${ }^{3}$ I therefore studied the geographical distribution of suicide in Scotland.

\section{Subjects, methods, and results}

Data on deaths from suicide (ICD (ninth revision) codes 950-959), accidental poisoning (ICD codes 850-869), and deaths undetermined, whether accidentally or purposely inflicted (ICD codes 980-989), during 1974-86 for the 56 local government districts were obtained as described previously.' Population data were obtained from the annual report of the registrar general (Scotland) for 1981. Standardised mortality ratios were calculated for each sex as described by Armitage $^{+}$by using five year age specific mortality rates and population data.

A total of 4054 men died by suicide during 1974-86. Standardised mortality ratios for local government districts covered a fivefold range from 39 to 226 (the value for Scotland as a whole is defined as 100). The figure shows that during 1974-86 almost all the highest rates of suicide among men occurred in northern Scotland. All eight districts in the highland region had standardised mortality ratios above 120 , and there were 95 more deaths from suicide than expected in this region. With two exceptions, low rates of suicide were found exclusively in the central belt of Scotland. This distribution was not simply due to chance variation in the rates because the same pattern was found when the districts with appreciably raised or lowered standardised mortality ratios were mapped (data not shown). Furthermore, the pattern was stable over time: when standardised mortality ratios were calculated separately for 1974-9 and 1982-6 six of the highland districts had standardised mortality ratios above 120 for both periods and nine of the central belt districts had standardised mortality ratios below 80 for both periods.

An analysis of the methods of suicide showed that suicides by drowning and hanging followed the gradient for all suicides most closely, but the

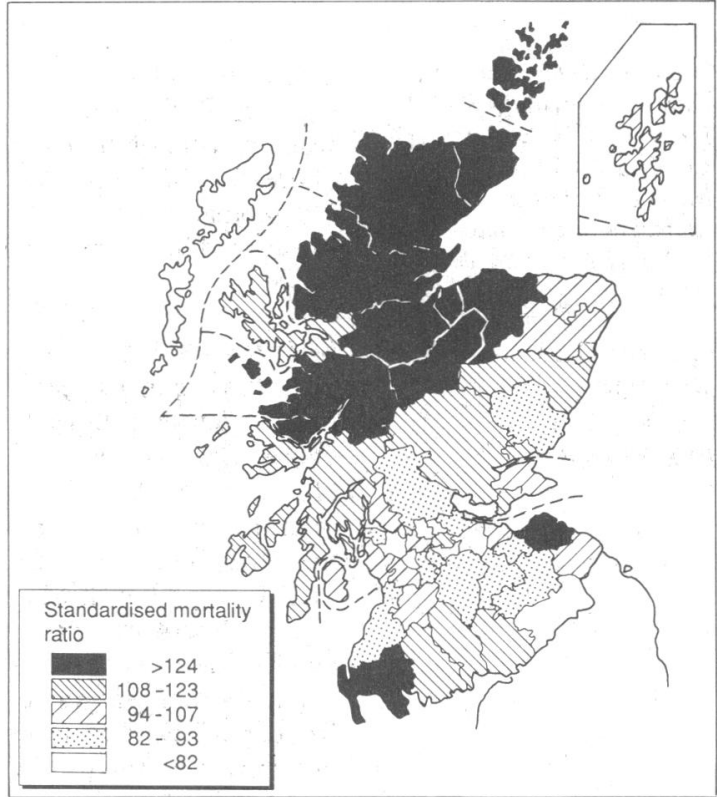

Geographical distribution of mortality from suicide among men in Scotland by local government district during 1974-86. Each range represents a fifth of distribution

pattern for the other methods was inconsistent. The geographical distribution could not be explained by regional differences in notification of suicide: when deaths from accidental poisoning and those that were undetermined were aggregated with the deaths from suicide the pattern was preserved.

The range in standardised mortality ratios for suicide among women (41 to 147) was less than that among men, and the association between the rates in the two sexes was weak (correlation coefficient $\mathrm{r}=0 \cdot 184, \mathrm{p}>0 \cdot 2)$. The geographical distribution of suicide among women was also harder to interpret, partly because their lower mortality rates were subject to much more sampling variation. Thus only three districts had appreciably raised standardised mortality ratios, two in the north of Scotland and one in the central belt. A map of standardised mortality ratios for women confirmed this weak and inconsistent pattern (data not shown).

\section{Comment}

The finding of a cluster of high mortality from suicide among men in the districts in the highlands of Scotland was unexpected. The districts with low mortality were in the central belt of Scotland, which is associated with high population density, heavy industry, and social disadvantage. Mental illness is by 